\title{
Comércio exterior e estruturas produtivas no Mato Grosso do Sul ${ }^{*}$
}

\author{
Lisandra Pereira Lamoso ${ }^{* *}$
}

\section{Resumo}

A economia de exportação possibilita compreender os usos do Território pelas corporações e compreender como o Território, ao reunir objetos técnicos e naturais, atrai determinados tipos de investimentos, compondo com as normas político-econômicas uma rede de características singulares. A política industrial vigente no Brasil tem contribuído para reforçar as estruturas produtivas baseadas no agronegócio e na exportação de minerais metálicos de baixo valor agregado, pelo Estado de Mato Grosso do Sul. O crescimento das exportações de produtos básicos tem sido acompanhado do aumento das exportações de semimanufaturados, embora um olhar atento revele que estes também fazem parte da cadeia produtiva do agronegócio, através da expansão da cana e do eucalipto. Essa configuração provoca uma extração da renda em favor das corporações internacionalizadas e inibe o processo de industrialização regional.

Palavras-chave: Comércio exterior; Agronegócios; Política industrial.

Foreign trade and productive structures in Mato Grosso do Sul

\begin{abstract}
The export economy helps to understand the uses of the Territory by corporations and understand how the Territory, by

* Pesquisa financiada pelo CNPq

** Universidade Federal da Grande Dourados - Parque Alvorada - MS (lisandralamoso@ufgd.edu.br).
\end{abstract}

Geosul, Florianópolis, v. 26, n. 51, p 129-144, jan./jun. 2011 
LAMOSO, L.P. Comércio exterior e estruturas produtivas no Mato ...

gathering technical objects both natural and artificial, attracts certain types of investments. All of this permeated by political and economic standards form a network of unique features. The current industrial policy in Brazil has contributed to strengthening the productive structures based on agribusiness and export of metallic minerals of low value added by the State of Mato Grosso do Sul The rise of commodity exports has been accompanied by increased exports of semi -industrialized, although a closer look reveals that these are also part of the agribusiness production chain through the expansion of sugarcane and eucalyptus. This setting causes an extraction of income by corporations internationalized and inhibits the process of regional industrialization.

Key words: Foreign trade; Agribusiness; Industrial policy.

\section{Introdução}

A função de fornecedor de bens primários é o papel tradicional desempenhado pelos países latino-americanos na Divisão Internacional do Trabalho. Ao longo dos séculos, essa participação passou por transformações socioespaciais nas principais economias. No Brasil, Chile, Argentina e México o processo de industrialização ocorreu com base no modelo de substituição de importações, desenvolvendo-se com peculiaridades que resultaram em maior internacionalização econômica (Brasil, Chile), maior subordinação à hegemonia norte-americana (México, Equador, Colômbia, Argentina até o Governo Menen), movimentos em busca de maior emancipação política (Venezuela, Bolívia, Brasil).

No caso brasileiro, a substituição de importações se desenvolveu segundo os impulsos partidos do centro dinâmico da economia capitalista, basicamente no seguinte movimento: em períodos de expansão da economia internacional houve um esforço de produção de mercadorias orientadas para o mercado exterior, para atender aos países do centro dinâmico do capitalismo. Segundo Rangel, "a economia brasileira, desde a descoberta, 
LAMOSO, L.P. Comércio exterior e estruturas produtivas no Mato ...

desenvolve-se como complemento de outras economias - dos países que, sucessivamente ocupam a vanguarda no desenvolvimento da humanidade" (RANGEL, 2005, p. 322). Nos períodos de contração econômica internacional, ocorreu um rearranjo das estruturas produtivas internas que possibilitou um movimento de substituição dos produtos importados.

$\mathrm{O}$ parque industrial formado predominantemente pelas intervenções diretas do Estado no setor produtivo (estatais) bem como pelos subsídios diretos ao capital privado nacional, que ocorreu com intensidade durante o período militar, resultou em volumes crescentes nas exportações de produtos semimanufaturados e manufaturados, acompanhados da redução das exportações de produtos primários (ver Figura 1). Em 1979 os dados das exportações por fator agregado apresentaram uma inversão das características primário-exportadoras brasileiras. Esse processo passou por uma fase de retrocesso nos primeiros anos do século XXI, como repercussões das políticas neoliberais de redução do Estado, privatizações, maior abertura às exportações e valorização cambial, implantadas durante os dois mandatos do Presidente Fernando Henrique Cardoso (1995-2003). A partir do ano 2000 houve uma tendência de aumento das exportações de bens primários e redução das exportações de produtos industrializados.

Bens primários e bens manufaturados são classificações por fator agregado. Segundo o Ministério do Desenvolvimento, Indústria e Comércio (MDIC, 2010), são três grandes classes que agrupam mercadorias com maior ou menor quantidade de transformação (agregação de valor) desde o início de seu processo produtivo até a venda final. Para o MDIC, os produtos industrializados dividem-se em semimanufaturados e manufaturados, uma vez mais considerando o grau de transformação.

1) semimanufaturado - produto que passou por alguma transformação. Ex: suco de laranja congelado; couro.

2) manufaturado - produto normalmente de maior tecnologia, com alto valor agregado, Ex: televisor, 
LAMOSO, L.P. Comércio exterior e estruturas produtivas no Mato ...

chip de computador, automóvel, CD com programa de computador, etc.

Nas exportações brasileiras por fator agregado, em percentuais, o comércio de produtos básicos tem apresentado crescimento na participação relativa do total desde o ano 2000, quando era de $22,8 \%$ e passou para $26,4 \%$ em 2001 , até alcançar $40,5 \%$ do total no ano de 2009 . As exportações de manufaturados começaram a diminuir na participação relativa do total no ano de 2000 , quando era de $59 \%$ e passou para $56,5 \%$ do total em 2001 até alcançar 44\% no ano de 2009 (Ver Figura 1).

\section{FIGURA 1}

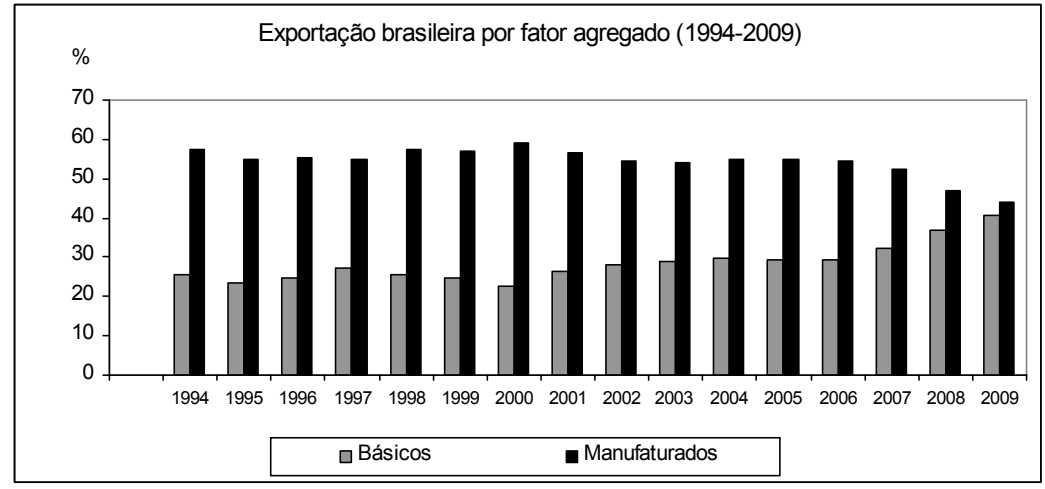

Fonte: Secex, 2010. Organização: Lamoso

Para a elaboração do gráfico da Figura 1, os dados absolutos em milhões de dólares FOB foram convertidos em porcentagens para visualizarmos a participação de cada classe no conjunto das exportações. Os dados absolutos são mascarados pelas alterações no câmbio, além dos dados relativos permitirem captar a perda de participação dos industrializados no mercado internacional.

O Governo Lula, em seu primeiro mandato (2003-2006), procurou reverter o desmonte do Estado através da implementação de políticas de planejamento de médio e longo prazo, colocando em 
LAMOSO, L.P. Comércio exterior e estruturas produtivas no Mato ...

vigor a Política Industrial, Tecnológica e de Comércio Exterior (PITCE) e posteriormente, no segundo mandato (2007-2010), a Política de Desenvolvimento Produtivo (PDP) (BARROS e PEREIRA, 2008). A PITCE foi elaborada no contexto de sucessivas crises internacionais que chamaram a atenção da América Latina após a derrocada do México e da Argentina, com o foco em três áreas de atuação: a) Promoção do desenvolvimento tecnológico e da inovação; b) Melhoramento da eficiência do sistema produtivo e c) Expansão das exportações (ALMEIDA, 2010).

A política do Governo pautou, estrategicamente, a expansão das exportações com o objetivo de manter os resultados da estabilidade financeira já adquirida e, ao mesmo tempo, procurar o que Coutinho (2003) chamou de "sustentabilidade macroeconômica". Para a manutenção da sustentabilidade macroeconômica o poder público avaliou que era condição sine qua non a obtenção de um elevado superávit comercial. O superávit teria como objetivo "reduzir a vulnerabilidade do balanço de pagamentos, recuperar um volume expressivo das reservas próprias de divisas e viabilizar uma queda segura e irreversível da taxa de juros" (COUTINHO, 2003, p.334).

Embora refém da estabilidade financeira, que coloca em pauta o controle inflacionário como principal medida econômica, e sem rompimentos radicais com o modelo herdado do antecessor (SADER,2010), a PDP retomou o planejamento de médio e longo prazo ao pautar um projeto de reconstrução nacional. No segundo mandato, o Governo Lula, ao diagnosticar que o país apresentava uma estrutura produtiva diversificada e com consideráveis vantagens comparativas na produção de produtos agropecuários, minerais e siderúrgicos, deu ênfase à ampliação das exportações.

A PDP traçou quatro macro-metas para a retomada do planejamento com visão de longo prazo: a) Aumento da taxa de investimento, ou seja, da formação bruta de capital fixo; b) Ampliação da participação das exportações brasileiras no comércio mundial; c) Elevação do investimento em Pesquisa \& Desenvolvimento e d) Ampliação do número de pequenas e médias 
LAMOSO, L.P. Comércio exterior e estruturas produtivas no Mato ...

empresas exportadoras. (MDIC, 2010). Com essa política em curso os subespaços da economia nacional tão variados quanto variadas são suas formações socioespaciais, inserem-se na economia internacional de forma distinta. Neste texto pretendemos, a partir da contextualização desse novo papel do Estado no planejamento, diagnosticar, num primeiro momento, como o Mato Grosso do Sul tem suas estruturas produtivas reorganizadas em função do estímulo ao comércio exterior.

Este texto está subdividido em duas partes, além dessa Introdução. $\mathrm{Na}$ segunda parte apresentamos as características principais da inserção da produção do Mato Grosso do Sul no comércio internacional com relação ao fator agregado. Na terceira parte destacamos os principais agentes exportadores e os mercados de destino. Nas considerações finais discutimos os reflexos da política de incentivo às exportações para o estado.

\section{A inserção de Mato Grosso do Sul no comércio internacional}

O papel de Mato Grosso do Sul como uma "extensão" da economia paulista, conforme foi apontado em trabalho de Goldestein e Seabra (1989) vem se confirmando no Mato Grosso do Sul desde seu processo de ocupação e povoamento, com a produção de arroz, café e gado, para o abate nos frigoríficos do interior paulista. A partir dos anos sessenta houve a expansão do cultivo da soja, enquanto a carne bovina continuou destinada ao mercado interno. $\mathrm{O}$ crescimento da produção de grãos (soja e milho), o tamanho médio das propriedades, os custos de produção e sua escala possibilitaram a expansão da agroindústria de aves e suínos, que se localiza preferencialmente na porção meridional do estado. Entre os dez produtos mais exportados também constam os minerais metálicos (minério de ferro granulado e manganês) extraídos da Morraria do Urucum, na planície do Pantanal.

Mais recentemente, além dos produtos do complexo soja (grãos, farelo) a carne bovina passou a integrar o rol dos principais 
LAMOSO, L.P. Comércio exterior e estruturas produtivas no Mato ...

produtos exportados, com tendência de perder esse posto para a pasta de celulose e para o açúcar/etanol.

A Figura 2 apresenta o comportamento das exportações do estado a partir do ano 2000, dividido em três categorias: produtos básicos, semimanufaturados e manufaturados. A média de exportações de produtos básicos de 1994 a 2009 foi de $77 \%$ do total. Para os produtos básicos (soja, minério de ferro) houve uma tendência de crescimento, com pequena inflexão de 2008 para 2009, que pode ser explicada pela redução das exportações de minério de ferro devido à crise financeira internacional.

A característica de economia agroprimária está expressa nos volumes exportados que caracterizam a forma de inserção do estado na economia internacional.

\section{FIGURA 2}

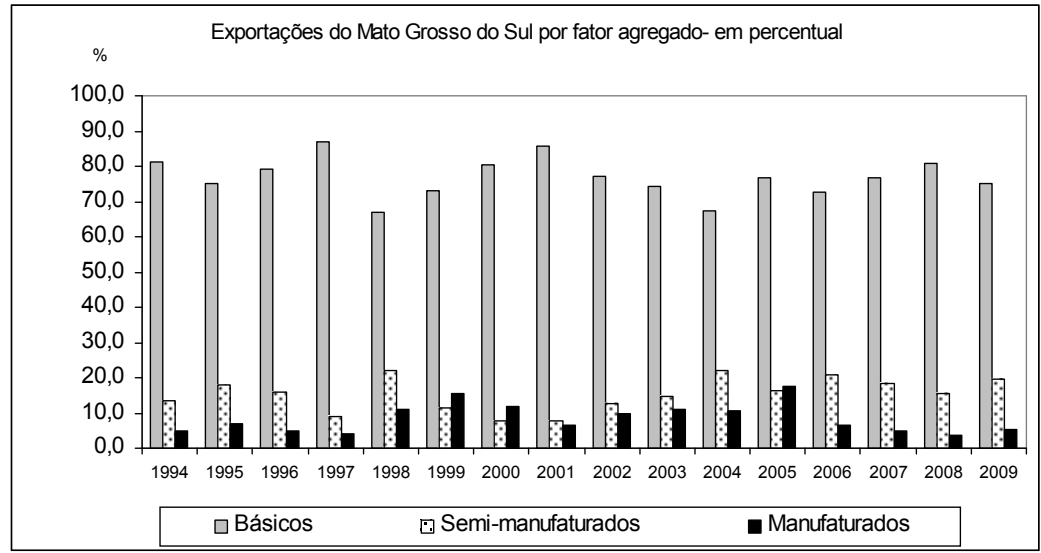

Fonte: Secex, 2010. Organização: Lamoso.

$\mathrm{Na}$ Figura 3, apresentamos um gráfico com os dados absolutos, em milhões de dólares FOB, considerando as exportações de produtos básicos e industrializados (nesse gráfico, o volume de industrializados resulta da soma de produtos semimanufaturados e manufaturados). Constatamos que as 
LAMOSO, L.P. Comércio exterior e estruturas produtivas no Mato ...

exportações de básicos se desenvolvem com picos de quatro em quatro anos, sempre de forma ascendente, mas que esse movimento não reduz os valores das exportações de produtos industriais. As exportações de básicos são determinadas pelas tradings de grãos e pela exportação de produtos minerais metálicos, enquanto as exportações de produtos industriais são realizadas pela produção agroindustrial de aves e suínos, indústria alimentícia de massas e biscoitos e pela expansão da pasta química de madeira, do complexo celulose e, mais recentemente pela exportação de açúcar.

\section{FIGURA 3}

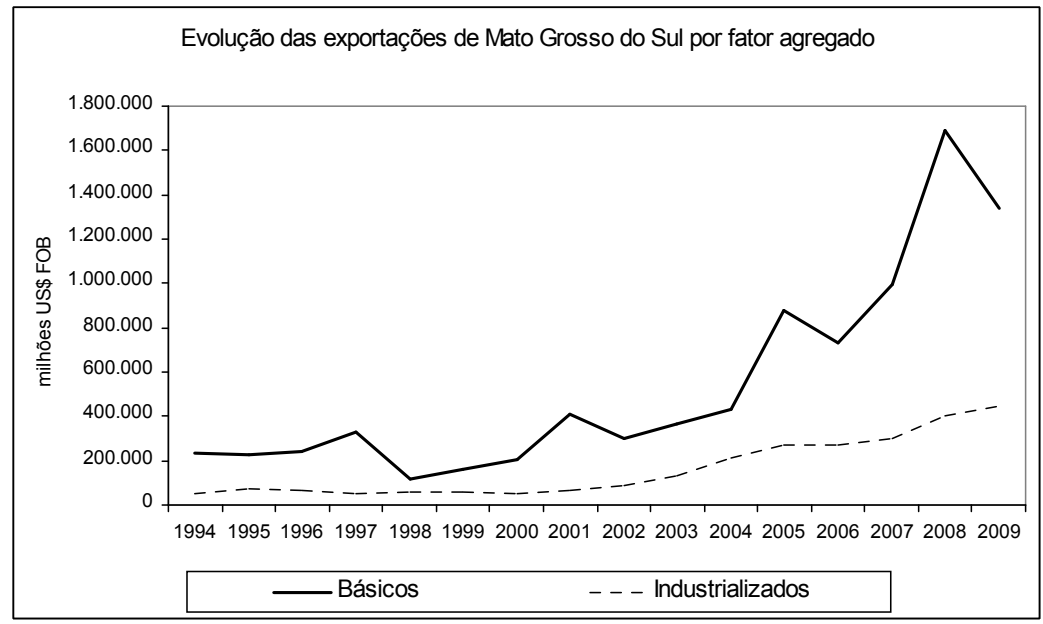

Fonte: Secex, 2010. Organização: Lamoso.

Para uma análise da pauta exportada de forma mais detalhada, utilizamos os dados da Secretaria de Comércio Exterior (SECEX, 2010) para o ano de 2009. Agrupamos os produtos exportados em torno da matéria principal e consideramos seus subprodutos (ver Quadro 1). Houve uma predominância da participação da pecuária e da soja na economia exportadora do estado, mas também estes mesmos produtos fazem parte do 
LAMOSO, L.P. Comércio exterior e estruturas produtivas no Mato ...

processo de industrialização em expansão. A carne bovina é abatida por unidades de frigoríficos instaladas no estado e a soja é também beneficiada, ainda que de forma bastante primária, pelas empresas do setor. Esse maior ou menor beneficiamento depende dos preços do produto no mercado internacional. O complexo soja liderou com $32,9 \%$ do total e a carne bovina com $24,4 \%$. Seguida pela participação da agroindústria de aves, com $12 \%$, cuja produção é fornecida à indústria por produtores integrados. $\mathrm{O}$ açúcar saiu da Tavares de Melo - Açúcar e Álcool. O grupo de minerais metálicos é monopolizado pela produção da Vale, em Corumbá e a pasta química de madeira pela Fibria (do Grupo Votorantim, que apareceu nos dados como VCP - MS Celulose), em Três Lagoas. Millho e soja são exportados pelas tradings Cargil, ADM, Bunge e por um conjunto de cooperativas que tem sede no norte do Paraná (C. Vale, Coamo e Lar).

QUADRO 1: Agrupamento dos principais produtos exportados por Mato Grosso do Sul e participação no total para o ano de 2009.

\begin{tabular}{cc}
\hline Produto principal e seus subprodutos & $\begin{array}{c}\text { Porcentagem da } \\
\text { participação no total }\end{array}$ \\
\hline
\end{tabular}

Soja em grão, farelo de soja, óleo de soja, semente para plantio, óleo degomado e refinado 32,9

Carne bovina congelada, refrigerada, tripa, couro, pele e outras miudezas

Aves congeladas, refrigeradas, miudezas

Açúcar em bruto

Minerais metálicos - minério de ferro granulado, minério de manganês, ferro-ligas

Pasta química de madeira

Milho em grão

2,4

Carne de suíno congelada e refrigerada e outras miudezas

Fonte: Secex, 2010. Organização: Lamoso. 
LAMOSO, L.P. Comércio exterior e estruturas produtivas no Mato ...

Organizamos os dados sobre a participação no total, das dezesseis maiores empresas exportadoras do estado (por valor exportado) para o ano de 2009, para completarmos o quadro das exportações.

TABELA 1: Participação das principais empresas exportadoras no total exportado pelo Mato Grosso do Sul no ano de 2009 e a variação entre 2008-2009.

\begin{tabular}{clcc}
\hline Ordem & \multicolumn{1}{c}{ Empresa } & $\begin{array}{c}\text { Participação } \\
\text { no valor total } \\
\text { em 2009 }\end{array}$ & $\begin{array}{c}\text { Variação } \\
\text { percentual } \\
\text { ocorrida de } \\
\text { 2008 para 2009. }\end{array}$ \\
\hline 1 & Bertin* & 11,71 & 219,14 \\
2 & ADM do Brasil Ltda. & 11,21 & $-21,13$ \\
3 & Seara Alimentos S/A & 8,47 & -17.73 \\
4 & Cargil Agrícola S/A & 7,49 & 69,25 \\
5 & JBS S/A & 4,64 & 11,03 \\
6 & Bunge Alimentos S/A & 4,54 & $-47,68$ \\
7 & VCP -MS Celulose & 4,20 & -- \\
8 & Tavares de Melo Açúcar e Álcool S/A & 4,01 & -- \\
9 & Urucum Mineração S/A & 3,65 & $-51,28$ \\
10 & Frigorífico Minerva S/A & 3,56 & 42,04 \\
11 & Frigorífico Independência S/A & 3,10 & $-74,10$ \\
12 & Doux-Frangosul S/A & 2,91 & $-2,20$ \\
13 & BRF Brasil Foods S/A & 2,80 & -- \\
14 & Coop. Agropecuária Mouraoense Ltda. & 2,39 & 160,48 \\
15 & Mineração Corumbaense Reunida S/A & 1,70 & $-75,69$ \\
\hline 16 & Louis Dreiffus Commodities S/A & 1,45 & $-60,20$ \\
\hline
\end{tabular}

* Incorporado pelo Grupo JBS.

Fonte: SECEX, 2010. Organizado por: Lisandra Lamoso.

A cadeia produtiva da carne bovina, cuja pecuária extensiva tem sido base da formação socioespacial do estado (BERTHOLI, 2006) recuperou os patamares anteriores ao embargo gerado pelos focos de febre aftosa, mas também refletiu a capacidade de abate, processamento e exportação do Grupo JBS, que é o maior produtor 
LAMOSO, L.P. Comércio exterior e estruturas produtivas no Mato ...

mundial do setor. As exportações da soja em grão, minério de ferro e açúcar apresentaram queda em função da redução da demanda por commodities e dos impactos da menor demanda chinesa para o período pós-crise de 2008. A orientação de incentivo às exportações manifestada nos créditos e incentivos fiscais fornecidos ao setor privado reforçou as estruturas produtivas baseadas nas corporações transnacionais e nos grupos privados especializados na produção de commodities, com atuação no agronegócio nacional e internacional.

A expressão territorial dos números da economia de exportação produz uma valorização da área que forma a Bacia do Rio Paraná, onde estão concentradas as estruturas produtivas voltadas para a exportação. Na Bacia do Rio Paraguai permanece, por força de efeitos naturais, a exploração de minerais metálicos em Corumbá, escoado pela Hidrovia do Rio Paraguai.

O Grupo JBS-Friboi, privilegiado com os aportes do BNDES, se fortaleceu tendo como localização a porção central do estado, na capital Campo Grande e em Naviraí, onde comprou a unidade do grupo Bertin. O Marfrig está localizado em Bataguassu, próximo ao estado de São Paulo. Este grupo está diversificado e atua não só no setor de carne bovina como também é proprietário da Seara Alimentos (com unidades nos municípios de Sidrolândia e Dourados). O complexo soja está localizado no divisor das bacias, no eixo da BR 163 e no eixo da Ferronorte, que são canais que permitem a fluidez e a eficiência do planejamento logístico. $\mathrm{O}$ crescimento da produção de celulose é acompanhado da expansão da área de reflorestamento, que ocupa a Região do Bolsão e tem sua centralidade no município de Três Lagoas, com a instalação da Fibria e, a partir de 2011, da atuação da Eldorado do Brasil, outro grande grupo industrial de celulose constituído com aportes do BNDES, que pertence ao JBS e à MCL empreendimentos.

Nesse processo, as estruturas produtivas formam territórios de exportação com maior concentração na porção meridional do estado, onde atuam as cooperativas (Coamo, C. Vale, Lar), tradings (Bunge, Cargil, Dreiffus), agroindústria de aves e suínos e 
LAMOSO, L.P. Comércio exterior e estruturas produtivas no Mato ...

os frigoríficos. Para Veltz (1996), que trabalha com a noção de "territórios-rede", os territórios são mais que repositórios de objetos técnicos. Os territórios exportadores apresentam um conjunto de relações imateriais. Estas também são apropriadas pelas empresas, como a tradição econômica, a experiência acumulada pelos agentes econômicos e políticos, o conhecimento dos trâmites da comercialização, do crédito, as relações com os prestadores de serviços como motoristas, mecânicos, escritórios de planejamento etc.

A organização em rede liga os territórios da exportação do estado com diversos e cada vez mais variados mercados internacionais. A infraestrutura se densifica na porção leste do estado, voltada para os portos do Oceano Atlântico.

$\mathrm{Na}$ Tabela 2 apresentamos os trinta maiores mercados consumidores da produção sul-matogrossense. Há predominância do mercado chinês (soja, aves e suínos). Federação da Rússia (carne bovina congelada), Hong Kong (aves e suínos), Argentina (minerais metálicos), França (grãos de soja e carne bovina). 
LAMOSO, L.P. Comércio exterior e estruturas produtivas no Mato ...

TABELA 2: Países de destino das exportações de Mato Grosso do Sul em 2009.

\begin{tabular}{|c|c|c|c|c|}
\hline Ordem & País de destino & $\begin{array}{c}\text { Milhões } \\
\text { dólares FOB }\end{array}$ & $\%$ & $\begin{array}{c}\text { Variação } \\
09 / 08\end{array}$ \\
\hline 1 & China & 289.476 .956 & 16,2 & $-24,1$ \\
\hline 2 & Federação da Rússia & 186.628 .088 & 10,5 & 0,9 \\
\hline 3 & Hong Kong & 104.894 .688 & 5,9 & 23,4 \\
\hline 4 & Argentina & 102.544 .125 & 5,7 & $-50,5$ \\
\hline 5 & França & 96.712 .124 & 5,4 & $-5,2$ \\
\hline 6 & Países Baixos & 96.597 .429 & 5,4 & $-8,1$ \\
\hline 7 & Arábia Saudita & 80.559 .724 & 4,5 & $-30,5$ \\
\hline 8 & Irá & 79.298 .180 & 4,4 & $-1,2$ \\
\hline 9 & Índia & 54.350 .856 & 3,0 & 283,1 \\
\hline 10 & Bolívia & 53.788 .298 & 3,0 & 323,1 \\
\hline 11 & Japão & 49.162 .797 & 2,8 & $-28,6$ \\
\hline 12 & Coréia do Sul & 43.740 .787 & 2,5 & $-1,6$ \\
\hline 13 & Emirados Árabes & 39.281 .380 & 2,2 & 93,5 \\
\hline 14 & Itália & 34.417 .439 & 1,9 & $-50,5$ \\
\hline 15 & Bangladesh & 29.985 .302 & 1,7 & 451,2 \\
\hline 16 & Estados Unidos & 27.616 .894 & 1,6 & $-69,1$ \\
\hline 17 & Egito & 22.908 .649 & 1,3 & $-50,1$ \\
\hline 18 & Paraguai & 20.286 .005 & 1,1 & $-1,0$ \\
\hline 19 & Espanha & 19.886 .848 & 1,1 & 16,5 \\
\hline 20 & Venezuela & 18.435 .109 & 1,0 & 0,4 \\
\hline 21 & Indonésia & 17.147 .121 & 1,0 & 95,2 \\
\hline 22 & Taiwan & 16.267 .562 & 0,9 & 178,0 \\
\hline 23 & Vietnã & 15.509 .825 & 0,9 & 111,9 \\
\hline 24 & Canadá & 14.775 .699 & 0,8 & 67,9 \\
\hline 25 & Romênia & 14.206 .889 & 0,8 & $-19,2$ \\
\hline 26 & Argélia & 13.334 .677 & 0,8 & 445,2 \\
\hline 27 & Líbano & 13.110 .716 & 0,7 & --- \\
\hline 28 & Alemanha & 11.888 .209 & 0,7 & $-75,2$ \\
\hline 29 & Eslovênia & 11.607 .379 & 0,7 & 549,4 \\
\hline 30 & Israel & 11.026 .860 & 0,6 & $-61,8$ \\
\hline 31 & Demais países & 195.938 .800 & 11,0 & $-29,4$ \\
\hline
\end{tabular}

Fonte: Secex, 2010. Organização: Lamoso. 
LAMOSO, L.P. Comércio exterior e estruturas produtivas no Mato ...

\section{Considerações finais}

As interações entre economia de exportação e as estruturas produtivas de Mato Grosso do Sul são intensas na medida em que a política industrial em vigor (Política do Desenvolvimento Produtivo) estimula o comércio exterior como parte do processo de desenvolvimento econômico desejado para o país. Tal política privilegia o fortalecimento dos grupos privados nacionais com aportes de capital público e resultam no fortalecimento do setor do agronegócio que atua no Mato Grosso do Sul.

Este setor abrange a classe dos pecuaristas (subordinados ao capital industrial e comercial dos grupos frigoríficos), do complexo soja (dominado pelas tradings transnacionais e pelas cooperativas exportadoras, entre as quais maior destaque cabe à Coamo) e pela produção de minério, exportado predominantemente na forma de minério granulado pela Vale.

Essa configuração provoca uma extração da renda para as matrizes dos grupos exportadores, tanto internacionais quanto aqueles localizados no próprio território nacional em outras unidades da federação. Paralelo ao aumento das exportações de produtos básicos já tradicionais do agronegócios (carne bovina e grãos), tem havido um aumento na participação de semimanufaturados. Estes volumes são representados pelo crescimento do setor sucroenergético e da produção de celulose.

Este modelo coloca na agenda de pesquisa a preocupação com a internacionalização das terras e a necessidade de reforçar as políticas de diversificação de renda e emprego, pois as oscilações no mercado de commodities tendem a afetar direta e agressivamente as estruturas produtivas, o emprego, a renda e as externalidades negativas postas pela questão ambiental. 
LAMOSO, L.P. Comércio exterior e estruturas produtivas no Mato ...

\section{Referências bibliográficas}

ALMEIDA, Mansueto. Desafios da real política industrial brasileira do século XXI. Textos para Discussão. São Paulo: IPEA, 2010. Versão para revisão. 71p.

BARROS, Octavio de; PEREIRA, Robson Rodrigues. Desmistificando a tese da desindustrialização: reestruturação da indústria brasileira em uma época de transformações globais. In: BARROS Octavio de; GIAMBIAGI, Fabio (Org.) Brasil globalizado. Rio de Janeiro: Campus, 2008. p.299-330.

BERTHOLI, Anderson. O lugar da pecuária na formação sócioespacial sul-matogrossense. 2006. Dissertação (Mestrado em Geografia). Centro de Filosofia e Ciências Humanas. Universidade Federal de Santa Catarina, 2006.

COUTINHO, Luciano; SARTI, Fernando. A política industrial e a retomada do desenvolvimento. In: LAPLANE, Mario et. al. Internacionalização e desenvolvimento da indústria no Brasil. São Paulo: Editora da Unesp/Instituto de Economia da Unicamp, 2003. p.333-347.

GOLDENSTEIN, Lea; SEABRA, Manoel. Divisão regional do trabalho e nova regionalização. In Secretaria de Estado de Educação de São Paulo. Fundamentos para o ensino de geografia - seleção de textos. São Paulo, CENP, 1989, p.45-69.

MINISTÉRIO DO DESENVOLVIMENTO, INDÚSTRIA E COMÉRCIO. Estatísticas de comércio exterior - DEPLA.< http://www.mdic.gov.br > Acesso em: 25 ago. 2010.

SECEX. Fator agregado - explicação. Disponível em http://www.mdic.gov.br//arquivos/dwnl_1283455528.doc Acesso em: 17 de novembro de 2010. 
LAMOSO, L.P. Comércio exterior e estruturas produtivas no Mato ...

. Política de Desenvolvimento Produtivo. Disponível em $<$ http://www.mdic.gov.br/pdp/ > Acesso em: 2 de set. 2010.

RANGEL, Ignácio. Ciclo, tecnologia e crescimento. In: BENJAMIM, Cesar (org). Obras reunidas. v.2, São Paulo: Contraponto, 2005. p. 255-408.

Recebido em março de 2011 Aceito em setembro de 2011 